\title{
Focusing on the quality and performance implications of marketing analytics
}

\author{
Maria Petrescu ${ }^{1} \cdot$ Anjala S. Krishen ${ }^{2}$
}

Revised: 2 August 2021 / Accepted: 2 August 2021 / Published online: 9 August 2021

(c) The Author(s), under exclusive licence to Springer Nature Limited 2021

The Journal of Marketing Analytics emerged in 2013 from Palgrave Macmillan as a merger between the Journal of Targeting, Measurement and Analysis for Marketing (2001-2012), (present on all major journal ranking lists, including ABDC and ABS) and the Journal of Database Marketing and Customer Strategy Management (2001-2012), also included on most ranking lists. The Journal of Marketing Analytics is a peer-reviewed journal that publishes four print and online issues per year, provides a single accessible resource for the rapidly changing field of marketing analytics, and combines the best of applied scientific research and commercial best practices on this topic. We cover all related areas including research methods, targeting, segmentation, big data, customer loyalty, CRM, data quality management, software, marketing strategy, and more.

The JMA has evolved alongside research and industry interests in business and marketing analytics. As illustrated in Figs. 1 and 2, from 2004 to 2021, Google searches for "business analytics" and "marketing analytics" increased significantly, peaking between 2018 and 2019. Developing and maturing with this increase in interest, our journal has gradually been included among its predecessors on the major indexes and journal ranking lists, including the most restrictive Australian Business Deans Council (ABDC) and the Chartered Association of Business Schools (ABS).
We are led to reflect on the evolution of marketing analytics, potential new areas of research it might produce, the quality of its deployment, as well as its performance implications (Germann et al. 2013; Iacobucci et al. 2019; Petrescu et al. 2020; Sheth 2021). As marketing analytics is a diverse field, researchers and practitioners have various backgrounds including marketing, data science, and information systems. This diversity of thought emphasizes the need for clearer implementation and quality standards, an under-researched area in analytics (France and Ghose 2019; Germann et al. 2013). Moreover, data-driven marketing research and practice require more studies to form standards regarding the key implementation and management of quality elements of analytics, from a supportive analytics culture to the appropriate data and information technology support framework (Germann et al. 2013; Sheth and Kellstadt 2021). Hence, as a next phase in the evolution of the JMA, we encourage more integrative, multidisciplinary articles focusing on the challenges and performance implications of marketing analytics implementation. We also appreciate research on management, quality standards, adaptation to data-driven marketing requirements, as well as links to other related fields, such as data science and operations.

Maria Petrescu

petrescm@erau.edu

Anjala S. Krishen

anjala.krishen@unlv.edu

1 Embry-Riddle Aeronautical University, Daytona Beach, FL, USA

2 Lee Business School, University of Nevada, Las Vegas, Las Vegas, NV, USA 


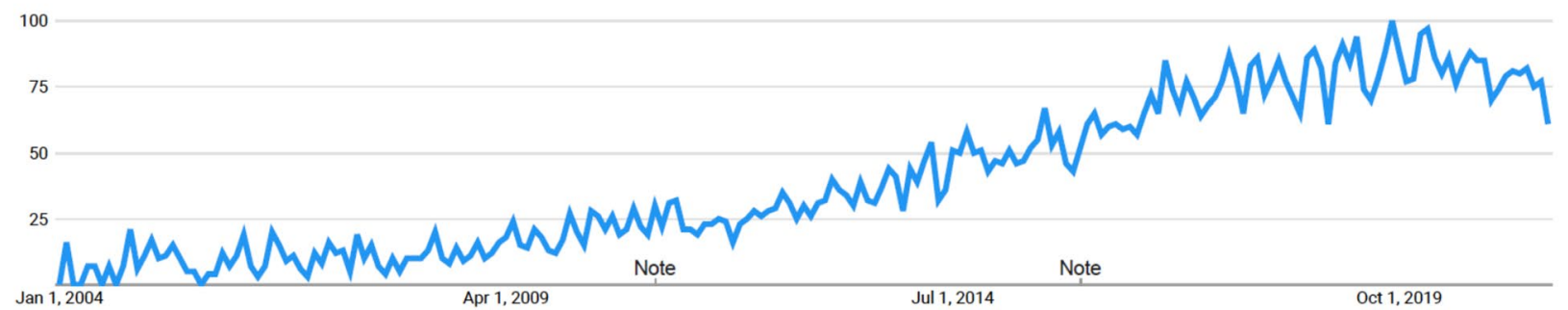

Fig. 1 Google search "business analytics"

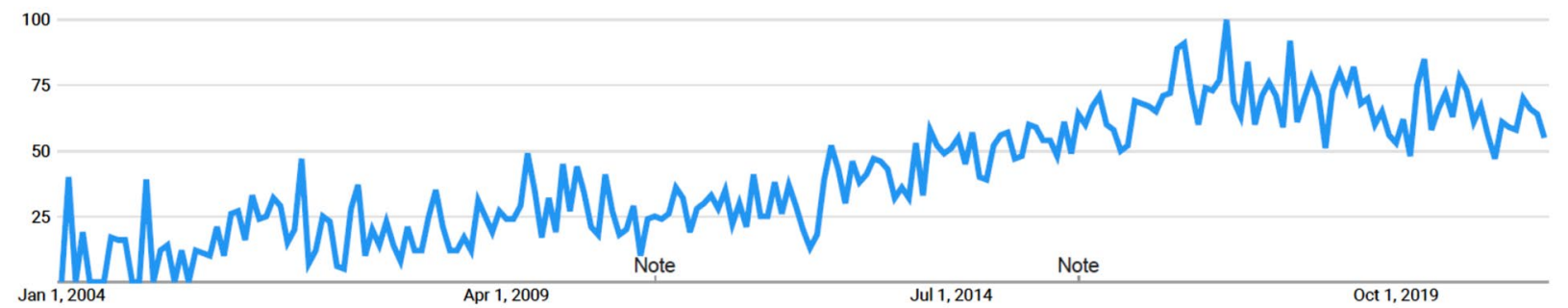

Fig. 2 Google search "marketing analytics"

\section{References}

France, S.L., and S. Ghose. 2019. Marketing analytics: Methods, practice, implementation, and links to other fields. Expert Systems with Applications 119: 456-475.

Germann, F., G.L. Lilien, and A. Rangaswamy. 2013. Performance implications of deploying marketing analytics. International Journal of Research in Marketing 30 (2): 114-128.

Iacobucci, D., M. Petrescu, A. Krishen, and M. Bendixen. 2019. The state of marketing analytics in research and practice. Journal of Marketing Analytics 7 (3): 152-181.

Petrescu, M., A. Krishen, and M. Bui. 2020. The internet of everything: Implications of marketing analytics from a consumer policy perspective. Journal of Consumer Marketing 37 (6): 675-686.

Sheth, J. 2021. New areas of research in marketing strategy, consumer behavior, and marketing analytics: The future is bright. Journal of Marketing Theory and Practice 29 (1): 3-12.

Sheth, J., and C.H. Kellstadt. 2020. Next frontiers of research in data driven marketing: Will techniques keep up with data tsunami? Journal of Business Research 125 (May): 780-784.

Publisher's Note Springer Nature remains neutral with regard to jurisdictional claims in published maps and institutional affiliations.
Maria Petrescu is an Assistant Professor of Marketing at Embry-Riddle Aeronautical University. Her main research areas include marketing analytics and digital marketing. She has published articles in journals such as Psychology \& Marketing, the Journal of Marketing Management, Public Management Review, Journal of Product and Brand Management, the Journal of Retailing and Consumer Services, and the Journal of Internet Commerce.

Anjala S. Krishen is a Professor of Marketing and International Business and Director of MBA Programs at University of Nevada, Las Vegas and has a B.S. in Electrical Engineering from Rice University and an M.S. Marketing, MBA, and Ph.D. from Virginia Tech. She held management positions for 13 years before pursuing a doctorate. As of 2021, she has published over 65 peer-reviewed journal papers in highly ranked journals. In 2016, she gave a TEDx talk (at UNR) titled "Opposition: The light outside of the dark box," and a UNLV Creates speech entitled "Consuming to Creating, Watching to Doing, Seeing to Being." To date, she has completed over 65 marathons, seven ultramarathons, and fve 100 milers and has a black belt in Taekwondo. 